\title{
AS PESQUISAS GEOLINGUÍSTICAS DO PORTUGUÊS DO BRASIL
}

\author{
GEOLINGUISTIC SURVEYS OF BRAZILIAN PORTUGUESE
}

\author{
Maria do Socorro Silva de Aragão
}

\section{Resumo:}

Os estudos dialetológicos, em sentido amplo, e a geografia linguística, em particular, não tinham, até 45 anos atrás, tradição no Brasil. A publicação de seis Atlas linguísticos regionais, entre os quais o da Paraíba, abriu caminho para novos Atlas que se encontram em diferentes estágios de elaboração e em fase de publicação. Nesse artigo, são comentados esses Atlas, ressaltando que eles possibilitaram a oportunidade e as condições para o início das pesquisas do Atlas Linguístico do Brasil-AliB, em fase inicial de elaboração.

Palavras chave: Geolinguística. Atlas Linguístico. Estudo comparado.

\begin{abstract}
:
Dialectological studies, in a broad sense, and linguistic geography, in particular, had no tradition in Brazil until 45 years ago. The publication of six regional Linguistic Atlas, including that of Paraíba, paved the way for new Atlas that are in different stages of elaboration and in the publication phase. In this article, these Atlas are commented, emphasizing that they provided the opportunity and the conditions for the beginning of the research of the Linguistic Atlas of Brazil-AliB, in the initial phase of elaboration.

Keywords: Geolinguistics. Linguistic Atlas. Comparative study.

\section{Introdução}

O português do Brasil, apesar de não ter grande tradição em estudos dialetais e geolinguísticos, a exemplo do português de Portugal ou de outras línguas da Europa e do inglês americano, tem demonstrado grande vitalidade nas duas últimas décadas.
\end{abstract}


Graças aos projetos de pesquisa desenvolvidos nas Universidades, especialmente nos cursos de pós-graduação, os aspectos dialetais do português do Brasil vêm sendo analisados, utilizando-se, para isto, diferentes correntes e modernas teorias linguísticas.

A publicação de seis Atlas Linguísticos Regionais: Bahia, Minas Gerais, Paraíba, Sergipe, Paraná e da Região Sul (Paraná, Santa Catarina e Rio Grande do Sul), abriu caminho para novos Atlas que se encontram em diferentes estágios de elaboração e em fase de publicação.

O resultado desse interesse pelos estudos dialetais e geolinguísticos e a experiência acumulada pelos pesquisadores durante todos esses anos, possibilitaram a oportunidade e as condições para o início das pesquisas do Atlas Linguístico do Brasil-AliB, em fase inicial de elaboração.

\section{Histórico}

Os estudos dialetológicos em sentido amplo, e a geografia linguística em particular, não tinham, até cerca de 40 anos atrás, tradição no Brasil.

Apesar do esforço de um grupo de pioneiros, como os professores Serafim da Silva Neto, Antenor Nascentes e Cândido Jucá Filho inicialmente e, posteriormente, dos professores Sílvio Elia, Celso Ferreira da Cunha, Nelson Rossi e Heinrich Bunse, poucos são os cursos de Dialetologia e Geografia Linguística em nossas universidades.

Essa quase inexistência dos cursos de Dialetologia nas universidades se constitui, talvez, no maior dos problemas para o desenvolvimento dos estudos dialetológicos. Tal fato forma um verdadeiro círculo vicioso. Não temos a disciplina porque não há especialistas. Conseqüentemente, não formamos especialistas, e assim sucessivamente. São raros, mesmo ainda hoje, os professores, em nossas Universidades, que se interessam pela Dialetologia no Brasil.

O professor Serafim da Silva Neto, um desses pioneiros, iniciou seus cursos de Dialetologia em 1951, na Universidade de Minas Gerais. Em 1953, fundou, no Museu Nacional do Rio de Janeiro, o Centro de Estudos de Dialectologia Brasileira e em 1954, ministrou curso de Dialetologia na Universidade do Rio Grande do Sul. Ainda em 1954, no $2^{\circ}$ Colloquium de Estudos Luso-Brasileiros, em São Paulo, propôs uma série de passos a serem dados para a concretização do estudo dos nossos falares. Em 1955, ministrou na Faculdade Nacional de Filosofia do Rio de Janeiro um curso sobre a técnica das monografias dialetais. Em 1958, o Instituto Nacional de Pesquisas da Amazônia publicou a $2^{\text {a }}$ edição melhorada e ampliada de sua obra "Guia para Estudos Dialectológicos", resultado de uma série de cursos e conferências proferidas na Faculdade Catarinense de Filosofia.

Como resultado desses cursos e da pregação do prof. Silva Neto o Centro de Pesquisas da Casa de Rui Barbosa, por sua Comissão de Filologia, propôs, através do 
Decreto $\mathrm{n}^{\mathrm{o}}$ 30.643, de 20 de março de 1952, em seu Art. $3^{\circ}$, como um de seus objetivos a elaboração do Atlas Linguístico do Brasil. Para a consecução desse objetivo, e a convite da Casa de Rui Barbosa, esteve no Rio, em 1954, o Professor Sever Pop que ministrou um curso, a partir do qual se esperava que surgissem pessoas interessadas em desenvolver pesquisas dialetológicas, o que não ocorreu.

Em 1957, Serafim da Silva Neto e Celso Ferreira da Cunha, no III Colóquio Internacional de Estudos Luso-Brasileiros, em Lisboa, apresentaram a ideia de um Atlas Linguístico-Etnográfico do Brasil, por regiões, tarefa que somente agora começa a ser cumprida, face às dificuldades inerentes a esse tipo de pesquisa, à dimensão continental do Brasil e à falta de uma coordenação nacional com o objetivo de uniformizar os objetivos, os métodos e o questionário para a realização de tão importante e necessário trabalho.

O professor Antenor Nascentes, outro dos precursores da Geografia Linguística no Brasil, publicou as "Bases para Elaboração do Atlas Linguístico do Brasil”, em duas partes. A primeira, em 1958, dedicada ao questionário geral e sugestão de pontos para o inquérito e a segunda, em 1961, com o questionário específico e o vocabulário piloto. Em seu trabalho diz o autor (Nascentes 1958:7) que:

Embora seja de toda vantagem um atlas feito ao mesmo tempo para todo o país, para que o fim não fique muito distanciado do princípio, os Estados Unidos, país vasto e rico e com excelentes estradas, entregou-se à elaboração de atlas regionais, para mais tarde juntá-los no atlas geral. Assim também devemos fazer em nosso país, que é também vasto e, ainda mais, pobre e sem fáceis vias de comunicação. ${ }^{1}$

A semente plantada por Serafim da Silva Neto e Antenor Nascentes deu frutos na medida em que professores e pesquisadores nas suas universidades vêm se dedicando aos estudos dialetológicos com a elaboração e publicação dos seis Atlas Linguísticos regionais, passo decisivo para a realização do Atlas Linguístico do Brasil.

A esse respeito, concordamos com Cardoso (Cardosos 1998:6) quando afirma na introdução do Projeto do Atlas Linguístico do Brasil:

O quadro histórico-social do Brasil, hoje, e a necessidade do conhecimento sistemático e geral da realidade linguística brasileira, necessário sobremodo à difusão de um ensino adequado ao caráter pluricultural do país, estão a exigir, sem mais demora, um esforço coletivo na tentativa de concretizar estudos mais amplos que levem a esse conhecimento global. Essa pode e deve ser tarefa da Dialectologia brasileira nesse final de milênio, a se concretizar com a realização do atlas linguístico geral do Brasil. ${ }^{2}$

1 NASCENTES, Antenor. Bases para a elaboração do Atlas linguístico do Brasil.vol.I, 1958, p. 7.

2 CARDOSO, Suzana A.M. Atlas linguístico do Brasil. Projeto. Salvador: UFBA, 1998, p. 6.

Vol. 25 - Ano $44-n^{\circ} 1-2020$ 


\section{Os Estudos Geolinguísticos no Brasil}

No que diz respeito aos estudos puramente geolinguísticos, o Brasil também evoluiu consideravelmente, embora não tanto quanto se desejasse. Aqui consideraríamos não apenas os estudos sobre falares regionais, mas sua colocação em cartas, ou mapas linguísticos, onde a dimensão geográfica fica muito mais evidente, sem, contudo, perder de vista os laços dialetais e sociolinguísticos. A distinção aqui feita dos estudos dialetais e geolinguísticos justifica-se por concordarmos com Coseriu quando define a geolinguística em relação à dialetologia. Diz ele:

Geografia linguística designa exclusivamente um método dialectológico e comparativo... e que pressupõe o registro em mapas especiais de um número relativamente elevado de formas linguísticas (fônicas, lexicais ou gramaticais)... ${ }^{3}$

Nos mesmos estudos a que nos referimos anteriormente, encontramos cerca de $14 \%$ de trabalhos realizados com falares regionais, devidamente cartografados, os Atlas, ou a eles referentes. Esses trabalhos, a exemplo do que se falou sobre as pesquisas dialetais, referem-se, na maioria, a aspectos léxicos e fonéticos dos falares regionais.

Quanto aos Atlas Linguísticos regionais brasileiros, vamos analisar os Atlas publicados, os em pleno andamento e os que estão se iniciando.

\subsection{Atlas Publicados}

\subsubsection{Atlas Prévio dos Falares Baianos}

O Atlas Prévio dos Falares Baianos se constitui em um marco nos estudos da Geografia Linguística no Brasil não só por ter sido o primeiro trabalho a ser publicado mas, por sua fundamental importância para o conhecimento do falar regional da Bahia e, por extensão, de grande parte do falar nordestino.

Publicado em 1963, o Atlas Prévio dos Falares Baianos constitui-se de dois volumes: o primeiro, compreendendo as cartas, em folhas soltas e o segundo, encadernado, com a introdução, questionário comentado e elenco das respostas transcritas.Está assim organizado:

- Localidades - 50 localidades.

- Informantes: 99

- Faixa etária: 25 a 84 anos.

- Nível de instrução: analfabeto e semi-alfabetizados

- Sexo: masculino e feminino.

3 COSERIU, E. A geografia linguística. In: O homem e sua linguagem. Rio de Janeiro/São Paulo: Presença/ USP, 1982, p. 79.

Vol. 25 - Ano $44-n^{\circ} 1-2020$ 
- Questionário

- Número de questões: 164.

- Tipo de Questionário: Semântico-Lexical

- Campos semânticos: agricultura, pecuária, anatomia e fisiologia humana, culinária e alimentação, geografia e astronomia.

- Apresentação das cartas

- Número de Volumes: 02, um com as cartas e um com o comentário das cartas

- Número de Cartas: 209,

- Tipo de Cartas: 11 de identificação, 154 fonéticas e léxicas e 44 cartas resumo. Os termos vêm transcritos no interior da própria carta ou com legendas e símbolos, em preto e branco e coloridos. Algumas cartas apresentam dados etnográficos, inclusive com ilustrações.

- Comentários: Nas cartas há comentários informativos sobre a aplicação do questionário. Os termos vêm transcritos no interior da própria carta ou com legendas e símbolos, em preto e branco e coloridos. Algumas cartas apresentam dados etnográficos, inclusive com ilustrações.

$\mathrm{O}$ volume referente à introdução, questionário comentado e elenco das respostas transcritas complementa as informações e análises feitas no Atlas. O Atlas não apresenta glossário nem bibliografia geral.

\subsubsection{Esboço de um Atlas Linguístico de Minas Gerais}

O segundo Atlas Linguístico publicado no Brasil é o de Minas Gerais, resultado do trabalho de um grupo de professores do Departamento de Letras da Universidade Federal de Juiz de Fora, Minas Gerais.Apresenta a seguinte organização:

- Localidades: 116 municípios.

- Informantes: 83.

- Faixa etária: 30 a 50 anos.

- Nível de instrução: analfabeto a primário completo.

- Sexo: masculino e feminino.

- Questionário

- $\quad \mathrm{N}^{\mathrm{o}}$ de questões: 415.

- Tipo de questionário: Semântico-lexical

- Campos semânticos: a terra, folguedos infantis.

- Apresentação das Cartas

- Número de volumes: 01

- Número de Cartas: 78

- Tipo de Cartas: 05 de identificação, 24 fonéticas, 21 léxicas, 03 isófonas e 25 isoléxicas. Os termos vêm com símbolos e legendas; na parte extrema esquerda das cartas constam os vocábulos de frequência mínima e na 
direita, os vocábulos de alta frequência, ficando no interior do mapa apenas os símbolos, círculos e triângulos cheios e vazios.

- Comentários: As cartas não trazem comentários informativos nem qualquer tipo de análise do material coletado. No final do volume há um glossário com 139 verbetes dicionarizados com acepção diferente ou não dicionarizados. A obra traz ainda uma bibliografia geral.

\subsubsection{Atlas Linguístico da Paraíba}

O terceiro Atlas Linguístico publicado no Brasil é o da Paraíba, resultado do trabalho de uma equipe de professores do Departamento de Letras Clássicas e Vernáculas da Universidade Federal da Paraíba, sob a coordenação das Profas. Maria do Socorro Silva de Aragão e Cleusa Palmeira Bezerra de Menezes.. O Atlas compreende três volumes, dos quais dois já publicados, com a seguinte estrutura:

- Localidades: 25 municípios base e 75 municípios satélite.

- Informantes: 107

- Faixa etária: 30 a 75 anos.

- Nível de instrução: analfabeto a primário completo.

- Sexo: masculino e feminino.

- Questionário

- $\quad N^{0}$ de questões: 877, sendo 289 do Questionário Geral e 588 do Questionário Específico

- Tipo de questionário: Semântico-lexical

- Campos semânticos : Questionário geral: a terra, o homem, a família, habitação e utensílios domésticos, aves e animais, plantação e atividades sociais.Questionário específico: mandioca, cana-de-açúcar, agave, algodão e abacaxi.

- Apresentação das cartas

- Número de volumes: 02:um com as Cartas e outro com as análises

- Número de Cartas:156

- Tipo de Cartas: 07 de identificação, 68 léxicas e 81 fonéticas. Os termos vêm com símbolos e legendas, ficando no interior do mapa apenas os símbolos.

- Comentários: As cartas não trazem comentários informativos nem qualquer tipo de análise do material coletado. O Atlas apresenta, ainda, um glossário, com 363 verbetes dicionarizados em sentido diferente do uso geral ou não dicionarizados. Cada verbete vem com a transcrição fonética da realização mais freqüente na região e a indicação, entre parênteses, do número da carta onde se encontra. 


\subsubsection{Atlas Linguístico de Sergipe I}

O Atlas Linguístico de Sergipe foi elaborado por pesquisadores que fizeram parte da equipe responsável pelo Atlas Prévio dos Falares Baianos: Carlota Ferreira, Jacyra Mota, Judith Freitas, Nadja Andrade, Nelson Rossi, Suzana Cardoso e Vera Rollemberg. O material, pronto desde 1973, somente foi publicado em 1987, com a seguinte organização:

- Localidades: 15 localidades.

- Informantes: 30

- Faixa etária: 25 a 65 anos.

- Nível de instrução: analfabetos e semi-analfabetos.

- Sexo: masculino e feminino.

- Questionário:

- $\quad \mathrm{N}^{\mathrm{o}}$ de questões: 700 .

- Tipo de questionário: Semântico-lexical

- Campos semânticos: terra, homem, animais, vegetais.

- Apresentação das Cartas

- Número de Volumes: 01

- Número de Cartas:180

- Tipo de Cartas: 11 de identificação, 169 léxicas e fonéticas. com transcrição pormenorizada.

- Comentários: As cartas contêm numerosos dados etnográficos, tendo em vista a quantidade de notas que acompanham as cartas. Em cada carta há a remissão à carta correspondente no Atlas Prévio dos Falares Bahianos. Há no ALS, ainda, uma série de cartas conjuntas Bahia-Sergipe, com dados da Bahia, não apresentados no APFB.O Atlas Linguístico de Sergipe não apresenta glossário.

\subsubsection{Atlas Linguístico de Sergipe II}

O Atlas Linguístico de Sergipe II acaba de ser concluído, como Tese de Doutoramento da Profa. Suzana Alice Cardoso, defendida no final de 2002, na Universidade Federal do Rio de Janeiro.

O Atlas, como Tese, compõe-se de dois volumes, com três tomos e um CD, com amostras dos questionários aplicados a 15 informantes.

- Localidades: 15 localidades.

- Informantes: 30

- Faixa etária: 25 a 65 anos.

- Nível de instrução: analfabetos e semianalfabetos.

- Sexo: masculino e feminino.

- Questionário:

- $\quad \mathrm{N}^{\mathrm{o}}$ de questões: 700 . 
- Tipo de questionário: Semântico-lexical

- Campo semântico: o homem.

- Apresentação das Cartas

- Número de Volumes: 02 em 03 tomos. O Volume I contém uma introdução, o tema numa perspectiva histórica, uma fundamentação teórica, a metodologia e uma bibliografia. O Volume II contém dois tomos, sendo o primeiro tomo dedicado à introdução das cartas, com os inquéritos, o questionário da área semântica homem, os critérios de apresentação das cartas, referências bibliográficas, índice de formas transcritas e índice onomasiológico. O segundo tomo do volume II é o dedicado às cartas

\subsubsection{Atlas Linguístico do Paraná}

O Atlas Linguístico do Paraná é um trabalho da Professora Vanderci de Andrade Aguilera, da Universidade Estadual de Londrina, Paraná, apresentado inicialmente como Tese de Doutorado e posteriormente publicado pelo Governo do Paraná e Universidade Estadual de Londrina. Compreende dois volumes: um com a Apresentação e o outro com as Cartas. Tem a seguinte estrutura:

- Localidades: 65 localidades.

- Informantes: 130

- Faixa etária: 25 a 65 anos.

- Nível de instrução: analfabeto e primário completo.

- Sexo: masculino e feminino.

- Questionário

- $\quad \mathrm{N}^{\mathrm{o}}$ de questões: 325 .

- Tipo de Questionário: Semântico-lexical

- Campos semânticos: I- Terra - a) natureza, fenômenos atmosféricos, astros, tempo; b) flora: árvores, frutos; c) plantas medicinais; d) fauna. II - Homem - a) partes do corpo, funções, doenças; b) vestuário e calçados; c) agricultura, instrumentos agrícolas; d) brinquedos e jogos infantis; e) lendas e superstições.

- Apresentação das cartas

- Número de Volumes: 02, um com a apresentação e outro com as cartas. $\mathrm{O}$ volume referente à Apresentação contém uma introdução; Esboço histórico da colonização paranaense; Pontos linguísticos investigados; Características dos informantes por localidade; Questionário linguístico; Notações fonéticas; Apresentação das cartas e notas.

- Número de Cartas: 203

- Tipo de Cartas: 06 de identificação, 92 léxicas, 70 fonéticas, 19 isoléxicas, 10 isófonas, 06 povoamento do Paraná nos séculos XVII a XX. Os termos nas cartas léxicas vêm com símbolos coloridos, no interior da carta, com 
as legendas do lado direito superior, fora da carta, e com as transcrições fonéticas no interior da carta, no caso das cartas fonéticas.

- Comentários: No verso de cada carta há notas explicativas e de análise do material coletado. O Atlas não apresenta glossário nem bibliografia.

\subsubsection{Atlas linguístico-etnográfico da região Sul do Brasil - ALERS}

Iniciado em 1980 e publicados os dois primeiros volumes em 2002. O ALERS envolve os Estados do Paraná, Santa Catarina e Rio Grande do Sul. O volume 1 é uma introdução e o volume 2 contém as cartas fonéticas e morfossintáticas. O ALERS tem a seguinte organização:

- Localidades: A pesquisa foi realizada em 294 Pontos, sendo 275 da zona rural e 19 da zona urbana, distribuídos pelos três estados do seguinte modo: Paraná -100 localidades da área rural e 06 urbanas. Santa Catarina - 80 rurais e 06 urbanas. Rio Grande do Sul - 95 rurais e 07 urbanas.

- Informantes: 664

- Faixa etária: 28 a 58 anos.

- Nível de instrução: analfabeto até à $4^{\mathrm{a}}$ série

- Sexo: masculino e feminino.

- Questionário

$N^{o}$ de questões: 700, subdivididas em mil itens

- Tipos de Questionários: Semântico Lexical, com 800 questões; Morfossintático, com 75 questões; Fonético - Fonológico com 26 questões de caráter geral e 24 específicas para as regiões de colonização não portuguesa.

- Campos semânticos: acidentes geográficos, fenômenos atmosféricos, astros e tempo, sistema de pesos e medidas, flora, atividades agro-pastoris, fauna, corpo humano, cultura e convívio, ciclos da vida, religião e crenças, festas e divertimentos, habitação, alimentação e cozinha, vestuário

- Apresentação das cartas

- Número de Volumes: 02, o volume 1 é uma introdução e o volume 2 contém as cartas fonéticas e morfossintáticas.

- Número de Cartas: 176, contudo, o total de cartas é maior que o número de cartas numeradas, 93, uma vez que há cartas desdobradas em a,b,c, e cartas combinadas 31/32/33(a). Após cada conjunto de cartas, vêm apêndices de itens sem carta, com o item, o número de ordem, o símbolo, a variante, a freqüência e o ponto onde ocorreu.

- Tipo de Cartas: 02 auxiliares, 70 fonéticas, 104 de morfossintaxe.

- Comentários: As cartas estão assim organizadas: Na parte superior à esquerda vêm o item do questionário e a legenda da carta; na parte superior à direita vem o número da carta. Na parte inferior à direita vêm os gráficos de freqüência. Nas páginas da direita vêm as cartas e nas páginas da 
esquerda vêm o item que constitui a carta, o número de ordem, o símbolo, a variante, a frequência e o ponto.

\subsection{Attas em Realização}

\subsubsection{Atlas Linguístico do Estado do Ceará}

O Atlas Linguístico do Estado do Ceará, em fase de publicação, é o resultado do trabalho de um grupo de professores do Departamento de Letras Vernáculas da Universidade Federal do Ceará, coordenados pelo Prof. José Rogério Fontenele Bessa, assessorado pelos professores José Alves Fernandes, Alexander F. Caskey, Hamilton Cavalcante de Andrade, Mário Roberto Lobuglio Zágari, Ignácio Ribeiro Pessoa Montenegro, José Pinheiro de Souza e José Carlos Gonçalves.

A pesquisa foi realizada em 69 municípios, com 268 informantes, pertencem à faixa etária entre 30 e 60 anos, com nível de instrução entre analfabeto a primário completo, de ambos os sexos.

As cartas são em número de 223, das quais 75 lexicais e 148 fonéticas.

O Atlas está no prelo, na Imprensa Universitária da Universidade Federal do Ceará.

\subsubsection{Atlas Linguístico do Estado de São Paulo}

O projeto de realização do Atlas Linguístico de São Paulo surgiu em 1980 sob a coordenação do Prof. Dr. Pedro Caruso, do Departamento de Linguística do Instituto de Letras, História e Psicologia da Universidade Estadual Paulista, Campus de Assis, São Paulo.

A pesquisa foi realizada em 120 localidades, com 240 informantes, na faixa etária de mais de 21 anos, de ambos os sexos, com nível de instrução entre analfabeto a curso primário completo.

Por se encontrar ainda na fase de organização e preparação do material coletado não há uma definição de como serão apresentadas as cartas e qual a estrutura formal a ser utilizada no Atlas Linguístico do Estado de São Paulo.

\subsubsection{Atlas Etnolinguístico dos \\ Pescadores do Estado do Rio de Janeiro}

O projeto do Atlas Etnolinguístico dos Pescadores do Estado do Rio de Janeiro APERJ, foi iniciado em 1985, sob a coordenação do Professor Celso Cunha, atualmente é coordenado pela Professora Silvia Figueiredo Brandão e conta com as pesquisadoras Maria Emília Barcellos da Silva e Edila Vianna da Silva.

A pesquisa foi realizada em 45 localidades localizadas em três regiões geográficas, com três localidades-piloto. Os informantes são das faixas etárias de 18 a trinta anos; 
31 a cinquenta anos e mais de 51 anos, do sexo masculino e com nível de instrução: analfabetos e alfabetizados.

\subsubsection{Atlas Etnolinguístico do Acre}

Projeto de Professores da Universidade Federal do Acre, coordenado pela Profa. Luíza Galvão Lessa, encontra-se em desenvolvimento.

A pesquisa foi realizada em três pontos em cada um dos três Vales que compõem o Estado do Acre. Os Informantes são da faixa etária entre 16 a cinquenta anos, de ambos os sexos, e analfabetos.

\subsubsection{Atlas Linguístico do Mato Grosso do Sul}

Projeto desenvolvido pelos professores Derci Oliveira, Aparecida Negri Isquerdo, Maria José Gomes e Albana Xavier Nogueira, da Universidade Federal do Mato Grosso do Sul.

A pesquisa está sendo realizada em 33 localidades, com informantes das faixas etárias entre 18 e trinta anos e entre 45 e setenta anos, de ambos os sexos, com nível de escolaridade entre analfabetos e de instrução elementar.

\subsubsection{Atlas Geo-Sociolinguístico do Pará}

Coordenado por Abdelhak Razky, da Universidade Federal do Pará, encontra-se desenvolvimento.

A pesquisa está sendo realizada em 57 localidades distribuídas em seis interregiões do Estado do Pará. Os informantes são de ambos os sexos, da zona rural e urbana.

\subsubsection{Atlas Linguístico do Estado da Amazônia}

Projeto de Tese de Doutorado de Maria Luíza de Carvalho Cruz, da Universidade Federal do Amazonas, em desenvolvimento.

A pesquisa de campo já concluída, foi realizada em 9 localidades divididas pelas microrregiões do Estado. Os informantes são em número de 54, sendo seis em cada ponto, três homens e três mulheres, em três faixas etárias de 18 a 35 anos, 36 a 55 anos e mais de 55. O nível de escolaridade é o de alfabetizados, tendo no máximo o curso elementar.

\subsection{Atlas Projetados}

\subsubsection{Atlas Linguístico do Rio Grande do Norte}

Projeto de um grupo de professores da Universidade Potiguar, em Natal, RN, sob a orientação da Profa. Maria das Neves Pereira. 
A pesquisa será desenvolvida em dez municípios, com informantes na faixa etária entre 18 e trinta anos e entre 45 e sessenta anos, de ambos os sexos, com escolaridade de alfabetizados até $4^{\text {a }}$ série do ensino fundamental.

\subsubsection{Atlas Linguístico do Maranhão}

O Atlas Linguístico do Maranhão encontra-se em fase inicial de elaboração, sob a coordenação da Profa. Conceição de Maria de Araújo Ramos, da Universidade Federal do Maranhão, em convênio com a Faculdade Atenas Maranhense.

A pesquisa será desenvolvida em 15 localidades, com 64 informantes, na faixa etária de 18 a trinta anos e de 45 a sessenta anos, de ambos os sexos, com nível de escolaridade de escolarizados até, no máximo, a $4^{\text {a }}$ série do ensino fundamental.

\subsubsection{Atlas Linguístico do Mato Grosso}

Projeto em fase preliminar de realização, coordenado pelo Prof. José Leonildo Lima, com a participação dos Professores Judith Albuquerque, Antônio Tadeu de Azevedo, Cássia Regina Tomanin, Liliane Batista Barros, Maria José Marques, Valéria Cardoso, Wellington Quintino e Zeneide Souza.

A pesquisa, em fase inicial, será realizada em 22 localidades, com um questionário que está sendo testado experimentalmente.

\section{Considerações Finais}

Pelo que se pode observar a partir da rápida análise acima realizada, num país com a dimensão territorial do Brasil, com 26 estados e o Distrito Federal, ainda é muito pouco o que foi realizado ou está em elaboração em termos de Dialetologia e, menos ainda, no que concerne à Geografia Linguística.

Permanecem bastante atuais as palavras de Mário Marroquim quando, já em 1934 dizia:

Não está ainda feito o estudo do dialeto brasileiro. A enorme extensão geográfica em que o português é falado no Brasil dá a cada região peculiaridade e modismos desconhecidos nas outras, e exige, antes da obra integral que fixe e defina nossa diferenciação dialetal, trabalhos parcelados, feitos com critério e honestidade, sobre cada zona do país. ${ }^{4}$

Tal fato tem se refletido negativamente no ensino da Língua Portuguesa em nosso país, por não haver, em termos das variantes diatópicas e diastráticas, um maior

4 MARROQUIM, M. A língua do nordeste. Curitiba: HDLivros, 198-96, p. 9.

Vol. 25 - Ano $44-\mathrm{n}^{\circ} 1-2020$ 
conhecimento da realidade linguística regional e nacional, pois concordamos com Tarallo (1985), quando diz que:

O Atlas linguístico de uma comunidade pode, por exemplo, fornecer dados valiosíssimos para o estudo de variação fonológica ou mesmo lexical. ${ }^{5}$

O professor Serafim da Silva Neto, no seu Guia para os Estudos Dialetológicos no Brasil, propôs uma série de sugestões para um incremento maior dos estudos de Dialetologia e Geografia Linguística entre nós, que permanecem atuais, apesar do tempo em que foram feitas, e que, se seguidas, certamente fariam com que esses estudos se desenvolvessem mais segura e rapidamente.

Como um princípio de solução, no Simpósio Sobre a Diversidade Linguística no Brasil, realizado na Universidade Federal da Bahia, em outubro de 1986, foi aprovada a proposta de criação de um grupo de trabalho para a uniformização de uma metodologia, inclusive de um questionário básico, para a elaboração de Atlas Linguísticos Regionais, visando a uma futura realização do Atlas Linguístico do Brasil.

Em 1996, na mesma Universidade Federal da Bahia, durante o Seminário Caminhos e Perspectivas para a Geolinguística no Brasil, foi criado o Comitê Nacional do Projeto Atlas Linguístico do Brasil, constituído de autores de Atlas Linguísticos Regionais já publicados e de um representante dos Atlas em andamento. Foi, assim, dado o passo definitivo para a realização do Atlas Linguístico do Brasil, agora em pleno desenvolvimento.

Como consequência dessas preocupações dos estudiosos na problemática dos estudos dialetais e, especialmente, da Geografia Linguística em nosso país, através de gestões e mesmo pressões junto aos órgãos governamentais de fomento e apoio à pesquisa, como o CNPq, Finep e Secretarias Estaduais de Ciência e Tecnologia, por exemplo, as portas começam aos poucos a se abrir, sendo aprovados alguns dos projetos nessa área, possibilitando, assim, as condições mínimas necessárias para a realização desse tipo de trabalho.

Apesar de todos os contratempos, carências e problemas até aqui apontados, cremos que a situação atual é das mais promissoras por já contarmos com modernos métodos de pesquisa, equipamentos e, acima de tudo, com recursos humanos bem treinados e motivados, levando-nos a esperar que os estudos de Geografia Linguística no Brasil venham em futuro próximo a assumir o papel de relevância que lhes cabe no âmbito dos estudos da Língua Portuguesa.

5 TARAllO, F. A pesquisa sociolinguística. São Paulo: Ática, 1985, p. 70.

Vol. 25 - Ano $44-n^{\circ} 1-2020$ 


\section{Referências}

AGUILERA, Vanderci de A.(1994/1995). Atlas linguístico do Paraná. Curitiba: Imprensa Oficial do Estado do Paraná / Londrina: Universidade Estadual de Londrina.

AGUILERA, Vanderci de A. (1994/1995). Atlas linguístico do Paraná. Apresentação. Curitiba: Imprensa Oficial do Estado do Paraná/Londrina: Universidade Estadual de Londrina.

ARAGÃO, Maria do Socorro Silva de et al.(1980). Atlas linguístico da Paraíba questionário. João Pessoa: Ed. Universitária/UFPB.

ARAGÃO, Maria do Socorro Silva de e MENEZES, Cleusa P.B.(1984). Atlas linguístico da Paraíba. Cartas léxicas e fonéticas. Brasília: CNPq/UFPB.

ARAGÃO, Maria do Socorro Silva de e MENEZES.(1984). Atlas linguístico da Paraíba. Análise das formas e estruturas linguísticas encontradas. Brasília: CNPq/UFPB.

ARAGÃO, Maria do Socorro Silva de.(1987).La situation de la géographie linguistique au Brésil. In: Geolinguistique, vol. III. Grenoble: Université Stendhall - Grenoble III.

ARAGÃO, Maria do Socorro Silva de e MENEZES.(1988).Bibliografia dialetal brasileira. João Pessoa: UFPB.

ARAGÃO, Maria do Socorro Silva de e MENEZES. (1997). A situação da geografia linguística no Brasil. In: GÄRTNER, E. (Org.) Pesquisas linguísticas em Portugal e no Brasil. Frankfurt am Main: Vervuert Verlag.

BESSA, José Rogério F. et al.(1982). Atlas linguístico do Ceará: questionário. Fortaleza: Universidade Federal do Ceará.

BLANCH, M.L.(1978). La sociolinguística y la dialectología hispánica. In: ALVAR, M \& BLANCH, M.L. En torno a la sociolinguística. México: UNAM.

BRANDÃO, Silvia Figueiredo.(1991). A geografia linguística no Brasil . São Paulo: Ática. BRANDÃO, Silvia Figueiredo. (1986). O atlas etnolinguístico dos pescadores do estado do Rio de Janeiro: propostas e caminhos. In: SIMPÓSIO SOBRE A DIVERSIDADE LINGUÍSTICA NO BRASIL, I. Atas. Salvador: UFBA, p. 139/145.

BUNSE, H.( 1969).Os estudos dialetais no Rio Grande do Sul: problemas, métodos e resultados. Porto Alegre: UFRGS.

Vol. 25 - Ano $44-n^{\circ} 1-2020$ 
CARDoso, Suzana A. M.(1998). Atlas linguístico do Brasil - ALiB - Projeto. Salvador: UFBA.

CARDOSO, Suzana A. M.(1999). A geolinguística no Brasil: meio século de contribuição à ciência da linguagem e ao ensino da língua materna. Boletim da ABRALIN, nº 23, p. 18-34.

CARDOSO, Suzana A. M.(2001-2002). La dialectologie au Brésil - Aperçue historique et bilan actuel. Geolinguistique Hors série nº 2. La géolinguistique em Amérique latine. Grenoble: Université Stendahal, Centre de Dialectologie, p. 197-229.

CARDOSO, Suzana A. M.(2002) Atlas linguístico de Sergipe II. Rio de Janeiro. Tese (doutorado) - UFRJ.

CARUSO, Pedro.(1983). Atlas linguístico do estado de São Paulo: questionário. Assis: Instituto de Letras,História e Psicologia/UNESP; Prefeitura Municipal de Assis.

COSERIU, E.(1982). A geografia linguística. In: O homem e sua linguagem. Rio de Janeiro/São Paulo: Presença/USP.

CRUZ, M. Luiza de C.(s.d). Atlas linguístico do Amazonas - Projeto. Manaus: UFAM.

CUNHA, C.F. da. Língua portuguesa e realidade brasileira.(1970).Rio de Janeiro: Tempo Brasileiro.

ELIA, Sílvio E. (1984). Atlas linguístico da Paraíba - apresentação. Brasília: CNPq/UFPB.

ELIZAINCÍN, A.(1988). Dialectología de los contactos: un ensayo metodológico. Annuario de Letras. México, v. XXVI.

FERREIRA, Carlota da S. et al.(1987). Atlas linguístico de Sergipe. Salvador: Instituto de Letras/Fundação Estadual de Cultura de Sergipe.

FERREIRA, Carlota da S. et al.(1995). A geografia linguística no Brasil. DELTA, vol. $11, \mathrm{n}^{\mathrm{o}} 2,255-277$.

FERREIRA, Carlota da S. et CARDOSO, Suzana Alice.(1994). A dialetologia no Brasil. São Paulo: Cortez.

KOCH,W.;KLASSMANN,M.S.; ALTENHOFEN,C.V. (Orgs.) (1002). Atlas linguísticoetnográfico da região Sul do Brasil. Porto Alegre/Florianópolis/Curitiba: Ed.UFRGS/ Ed.UFSC/Ed.UFPR, 2002. v. 1 e 2.

LESSA, Luiza G.(1989). Projeto atlas etnolinguístico do Acre - ALAC. Rio Branco: UFAC.

Vol. 25 - Ano $44-n^{\circ} 1-2020$ 
LIMA, J.L.(s.d.). Atlas linguístico do Mato Grosso - Projeto.Cuiabá: UFMT.

NASCENTES,Antenor.(1958/1961).Bases para a elaboração de um atlas linguístico do Brasil . Rio de Janeiro: Casa de Rui Barbosa, vol. I, vol.II.

NOGUEIRA, A. X.(1998). Notícias de um Atlas em andamento: Atlas linguístico de Mato Grosso do Sul - ALMS. In: AGUILERA, V. DE A. (Org.). A geolinguística no Brasil. caminhos e perspectivas. Londrina: UEL, p.143-154.

PEREIRA, M. das Neves.(2002). Atlas linguístico do Rio Grande do Norte Projeto. Natal: UNP.

RAMOS, Conceição de M.(2002). Atlas linguístico do Maranhão - Projeto. São Luís: UFMA/FAMA.

RAZKY, Abdelhak.(1998). O Atlas geo-linguístico do Pará: Uma abordagem metodológica. In: AGUILERA, V. DE A. (Org.). A geolinguística no Brasil. - caminhos e perspectivas. Londrina: UEL, p. 155-164.

RIBEIRO,José; Mário Roberto L. Zágari; José Passini; Antonio Pereira Gaio. Esboço de um atlas linguístico de Minas Gerais; questionário. s.n.t.

RIBEIRO,José; Mário Roberto L. Zágari.(1977). Esboço de um atlas linguístico de Minas Gerais. Rio de Janeiro: Fundação Casa de Rui Barbosa.

ROSSI, Nelson; FERREIRA, Carlota; ISENSEE, Dinah.(1963). Atlas prévio dos falares baianos. Rio de Janeiro: INL.

ROSSI, Nelson; FERREIRA. (1965). Atlas prévio dos falares baianos; introdução, questionário comentado, elenco das respostas transcritas. Rio de Janeiro: INL.

SILVA NETO, Serafim.(1955).Guia para estudos dialetológicos. Florianópolis: s. ed..

SILVA NETO, Serafim.(1958).Guia para estudos dialetológicos. Belém: INPA.

TARALLO, F. A pesquisa sociolinguística. São Paulo: Ática, 1985.

THUN, Harald et al.(1989). El atlas linguístico diatópico y diastrático del Uruguay (ADDU) Presentación de un proyeto. Iberoromânia,3. Tübingen: 26-62.

THUN, Harald; ELIZAINCÍN, Adolfo (Orgs.).(2000). Atlas linguístico diatópico y diastrático del Uruguay - ADDU. Kiel: Westensee Verlag. 